\title{
Trends of Opioid Utilisation in Denmark: A Nationwide Study
}

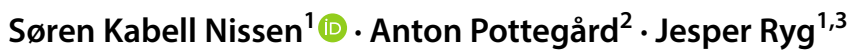

Published online: 18 September 2019

(c) The Author(s) 2019

\begin{abstract}
Background Opioid use has more than doubled over recent decades, and Denmark occupies fifth place in the global ranking. These increases have been partly attributed to the ageing population.

Objective Our objective was to assess the impact of age over time on utilisation of the most commonly used opioids in Denmark.

Methods We retrieved nationwide sales data on opioid sales in Denmark from 1999 to 2017. We investigated utilisation trends in age groups for the four opioids with the highest use. We used three volume-based metrics (defined daily doses/1000/ day, oral morphine equivalents/1000/day, and packages dispensed/year) and one person-based metric (users/1000/year).

Results The four opioids selected according to users/1000/year were tramadol (46.1), codeine and combination products (12.4 for codeine, 3.7 for codeine and acetylsalicylic acid, and 4.2 for codeine and paracetamol), morphine (17.0), and oxycodone (12.1). Overall utilisation according to volume and person metrics increased for all except codeine and combination products. Tramadol doses or strength increased, albeit less with increasing age. Oxycodone doses or strength decreased for all age groups but were nearly unchanged for the age group $\geq 80$ years.

Conclusion Tramadol is the most utilised opioid in Denmark and was prescribed at increasing doses or strengths over the study period, particularly in the younger ( $<80$ years) age groups. Overall, oxycodone was prescribed at decreasing doses or strengths over time but remained unchanged for the age group $\geq 80$ years. There is a need to address the pharmacological treatment of pain in terms of age, with tramadol and oxycodone being possible targets for regulatory efforts.
\end{abstract}

\section{Key Points}

We found age-dependent differences in utilisation patterns for oxycodone and tramadol.

Tramadol is the preferred opioid in all age groups, suggesting tramadol is an important drug to monitor, though oxycodone cannot be ignored.

Electronic supplementary material The online version of this article (https://doi.org/10.1007/s40801-019-00163-w) contains supplementary material, which is available to authorized users.

Søren Kabell Nissen

Soren.Kabell.Nissen@rsyd.dk

1 Department of Geriatric Medicine, Odense University Hospital, J. B. Winsløwsvej 4, 5000 Odense C, Denmark

2 Department of Public Health, University of Southern Denmark, Clinical Pharmacology and Pharmacy, J. B. Winsløwsvej 19, 3, 5000 Odense C, Denmark

3 Department of Clinical Research, University of Southern Denmark, J. B. Winsløwsvej 19, 3, 5000 Odense C, Denmark

\section{Introduction}

The prevalence of chronic pain is high and affects $12-30 \%$ of all Europeans, with a considerable impact on self-reported quality of life, posing a major international healthcare issue [1]. For some patients, opioids are used to treat chronic pain, and the total use of opioids more than doubled from 1999 to 2016 worldwide [2].

Denmark currently occupies fifth place in global opioid consumption rankings, with approximately twice the consumption of similar healthcare systems in Norway and Sweden $[3,4]$. This high ranking is alarming in light of the recently publicised "opioid epidemic" in the USA involving significantly more deaths from unintentional drug overdoses, likely driven by opioid misuse [5, 6].

In 2016, the Danish Health Authority mapped the use of opioids in Denmark and demonstrated an increasing consumption of opioids in general and tramadol in particular. Notably, unlike in Norway and Sweden, tramadol was omitted from prescription monitoring in Denmark until 2017 [3]. Treatment with opioids was more prevalent in the older population; hence, at least part of the increase was explained by the aging population [3]. 
In 2010 , it was estimated that $70 \%$ of costs related to the use of opioids in Denmark was for the indication chronic noncancer pain in the primary healthcare sector [11]. Recently, Denmark implemented a national guideline for the management of chronic ( $\geq 3$ months) non-cancer pain, adapted from the Canadian guideline [7-10]. The guideline does not advocate any specific weak or strong opioid for initiation of analgesic treatment but recommends an opioid trial, provided other pharmacological and non-pharmacological treatments have been tested and shown to be ineffective.

Both guidelines emphasise using oral morphine equivalents (OMEQs) for comparison of opioid doses, calculated from defined daily doses (DDD) in milligrams. OMEQs might provide better comparison of opioids of varying potency, as DDDs are based on the formal indications of the World Health Organization (WHO) [12-15].

Neither the Danish nor the Canadian guidelines contain recommendations relating to age, even though the prevalence of chronic non-cancer pain increases with age [16]. Furthermore, the use of opioids is an acknowledged risk factor for geriatric syndromes such as falls and delirium [17].

The Danish Health Data Authority provides public access to registers linking anonymized individual-level data with nationwide drug sale statistics [18], allowing for investigation of opioid sales trends on a national level [19]. Specifically, by combining volume metrics with the number of users receiving prescribed opioids, it is possible to investigate trends in opioid utilisation over time, as previously done by Karanges et al. [20].

We aim to assess utilisation trends in relation to age for the most commonly prescribed opioids in Denmark by combining volume-level metrics with person-level metrics and investigating the proportionality of these over time.

\section{Methods}

This study was conducted using national Danish data from 1 January 1999 to 31 December 2017.

\subsection{Setting}

Denmark has tax-supported universal healthcare with equal and free access. A reimbursement system provides standardised partial refunds on most prescribed drugs, including opioids.

\subsection{Data Sources}

Data on opioid use were retrieved from the Danish Health Data Authority, public access to which is provided via the web service Medical Statistics (MEDSTAT) [18, 19].
The MEDSTAT database provides on-demand nationwide aggregate statistics on drug use with linkage to individual-level prescription data in the primary care sector (since 1996) and in the hospital sector (since 1999), for all registered drugs sold in Denmark. The study ended in 2017 as the MEDSTAT database is updated annually, with a backlog of about 12 months.

Drug sales are registered according to anatomical therapeutic chemical (ATC) classification code.

It is possible to provide linkage at an individual level for prescription opioids, as a valid civil registration number is a prerequisite for obtaining prescription medicine.

Opioids administered while patients are in hospitals are not registered by prescriptions; instead, prescriptions for opioids are written at discharge or at ambulatory visits and dispensed at community pharmacies, thus captured in the MEDSTAT data source. Hence, age-linked data are only available for primary sector prescription dispensing [21].

Data on users collecting any prescription have been considered reliable since 1999 [18]. Sales data on drugs available over the counter (OTC) are also captured in the MEDSTAT database, albeit without linkage to individuallevel data as these are not registered for OTC sales.

When calculating the prevalence proportion of users for specific age groups, the denominator is not provided by MEDSTAT; instead, data on population size were retrieved from Statistics Denmark [22], also used by the MEDSTAT database, employing the same cut-off date of 1 January each year.

\subsection{Opioids}

We compiled data on opioid sales, divided into weak and strong potency subcategories [14].

All opioids are dispensed on prescription, except for some codeine and acetylic acid combination products (N02AJ07), which are also available OTC. It is not possible to age stratify OTC sales since these are not linked to a prescription.

The group of weak opioids encompassed codeine and paracetamol combination products (N02AJ06), codeine and acetylsalicylic acid combination products (N02AJ07), codeine (R05DA04), tramadol (N02AX02), and dextropropoxyphene (N02AC04). In 2009, the European Medicines Agency recommended the gradual withdrawal of dextropropoxyphene from the market [23], and no Danish dispensing has been registered since 2012 .

Codeine and acetylsalicylic acid combination products (N02AJ07) are also sold OTC under the following conditions: Packages containing 20 tablets of paracetamol $500 \mathrm{mg}+$ codeine $9.6 \mathrm{mg}$ are available for OTC sale in pharmacies provided the customer is aged $>18$ years. Sales of packages containing ten tablets of paracetamol 
$500 \mathrm{mg}+$ codeine $9.6 \mathrm{mg}$ are not restricted to pharmacies. Any dose, package size, or combination other than the above is prescription only.

The group of strong opioids included morphine (N02AA01), hydromorphone (N02AA03), nicomorphine (N02AA04), oxycodone (N02AA05), oxycodone and naloxone combination products (N02AA55), pethidine (N02AB02), fentanyl (N02AB03), buprenorphine (N02AE01), and ketobemidone and antispasmodic combination products (N02AG02).

No prescriptions were registered in the study period for morphine combinations (N02AA51) or pethidine and psycholeptic combination products (N02AB72). For fentanyl, only ATC group N02 was included, as N01 is reserved for anaesthetics.

\subsection{Data Analysis}

Opioid sales were studied in the period from 1999 to 2017. Utilisation patterns were investigated by comparing relative changes of three volume-based metrics and one personbased metric as previously done by Karanges et al. [20]. We selected the four most commonly prescribed opioids in 2017 and stratified sales data according to year and age group for the users (0-64, 65-79, and $\geq 80$ years). Utilisation patterns for prescription dispensing and OTC sales are presented separately.

The four opioids most commonly prescribed were identified according to the person-based metric prevalence proportion of users, defined as number of users dispensed at least one prescription per 1000 per year (users/1000/year).

The three volume-based metrics include packages dispensed per 1000 inhabitants per year (packages dispensed/1000/year), DDD per 1000 inhabitants per day (DDD/1000/day), and OMEQ per 1000 inhabitants per day (OMEQ/1000/day). The latter two metrics reflect standardised changes in utilisation (DDD) and corrected standardised changes according to potency (OMEQ). Utilisation data are presented according to opioid potency in two groups (weak and strong).

DDDs were converted to OMEQs, using best estimates of equianalgesic ratios for available formulations [3, 13, 14, 20], e.g. transdermal, per oral, parenteral, rectal, and suppository. The OMEQ value presented represents an aggregate of individually calculated OMEQs depending on the type of formulation of a given opioid [Table 1 in the Electronic Supplementary Material (ESM)].

For sales of codeine and acetylsalicylic acid combination products (N02AJ07), the share of prescription dispensing and OTC sales was retrieved. The majority of these sales reflected OTC sales, not linked to individual data, presented and analysed separately from prescription dispensing data.

\section{Results}

\subsection{Utilisation of Weak and Strong Opioids, Not Stratified by Age}

The most commonly prescribed opioids in 2017 according to users/1000/year were tramadol (46.1 users/1000/year), codeine including combination drugs (12.4 users/1000/ year for codeine, 3.7 users/1000/year for codeine and acetylsalicylic acid, 4.2 users/1000/year for codeine and paracetamol), morphine (17.0 users/1000/year), and oxycodone (12.1 users/1000/year) (Fig. 1). The fifth most commonly prescribed opioid, a comparatively much lower figure, was fentanyl (3.3 users/1000/year) (Table 2 in the ESM). These numbers do not account for users obtaining more than one opioid or multiple prescriptions for the same opioid in a given year.

During the study period, utilisation of weak opioids increased by $44 \%$ according to OMEQ/1000/day and decreased by $26 \%$ according to DDD/1000/day (Table 2 in the ESM). This contrast is caused by the increasing use of tramadol holding more weight in the calculation of OMEQs because of its higher potency than codeine and codeine combinations (Fig. 1; Table 2 in the ESM). Metrics in Fig. 1 do not include OTC sales of codeine and acetylsalicylic acid combination products.

Utilisation of strong opioids increased by $33 \%$ according to OMEQ/1000/day and 25\% according to DDD/1000/ day (Table 2 in the ESM). The difference is caused by oxycodone and fentanyl both increasing substantially (1152\% and $157 \%$, respectively) and both being more potent than morphine (Fig. 1; Table 1 in the ESM).

\subsection{Utilisation Trends of Most Prescribed Opioids, Not Stratified by Age}

Prescribed morphine, oxycodone, tramadol, and codeine with acetylsalicylic acid increased by all metrics, whereas codeine and codeine with paracetamol decreased by all metrics (Table 1; Fig. 1).

The percentage difference between DDD/1000/day and OMEQ/1000/day was either zero or negligible ( +0.3 percentage points for morphine) for all four opioids, as almost all registered sales of these drugs were exclusively for the oral formulation (Table 1 in the ESM); consequently, changes in OMEQ/1000/day are not displayed in Table 1.

Prescription dispensing of codeine and acetylsalicylic acid increased according to DDD/1000/day, with a concomitant decrease in DDD/1000/day for the OTC portion of sales (Fig. 1 in the ESM). This correlates with a limitation of OTC availability given the legal restrictions on package size imposed in 2013 in Denmark. 

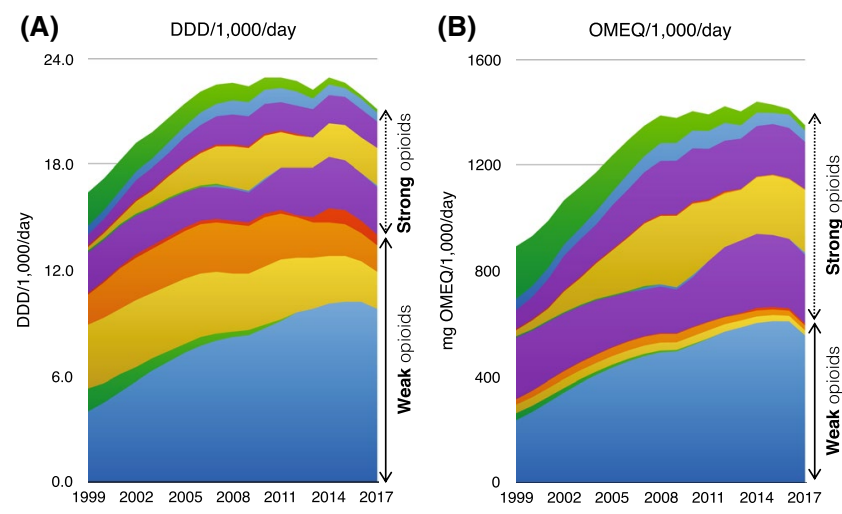

Fig. 1 Prescription dispensing trends of all opioids investigated, listed in layered two-dimensional diagrams according to analgesic potency (weak below and strong above) in a DDD/1000/day, b OMEQ/1000/

\subsection{Utilisations Trends of Selected Opioids, Age-Stratified}

For tramadol, increased utilisation according to DDD/1000/ day was not matched by an equally large increase in users/1000/year in any age group, with the relative change being less pronounced with increasing age (Table 1). As for tramadol, utilisation of codeine and acetylsalicylic acid combination products increased according to DDD/1000/ day, with a smaller increase in users/1000/day, though the relative changes were more pronounced with increasing age (Table 1).

In contrast, oxycodone utilisation increased according to $\mathrm{DDD} / 1000 /$ year but with a larger increase in users/1000/ year; the relative difference was smaller with increasing age (Table 1). Utilisation of morphine, like that of oxycodone, exhibited a larger increase according to users/1000/year than DDD/1000/day, but with nearly proportional relative changes of metrics when comparing age groups (Table 1).

Codeine utilisation diminished according to both metrics and did not display age-dependent differences, with nearly proportional relative changes of metrics in all age groups (Table 1).

Codeine and paracetamol combination products were utilised less according to DDD/1000/day, with a relatively larger decrease of users/1000/year; the difference was less pronounced with increasing age (Table 1).

Age-stratified metrics do not include OTC sales of codeine and acetylsalicylic acid combination products.

\section{Discussion}

This study demonstrated significant age-dependent trends in utilisation of select opioids in Denmark from 1999 to 2017. Further, it demonstrates an increasing utilisation of

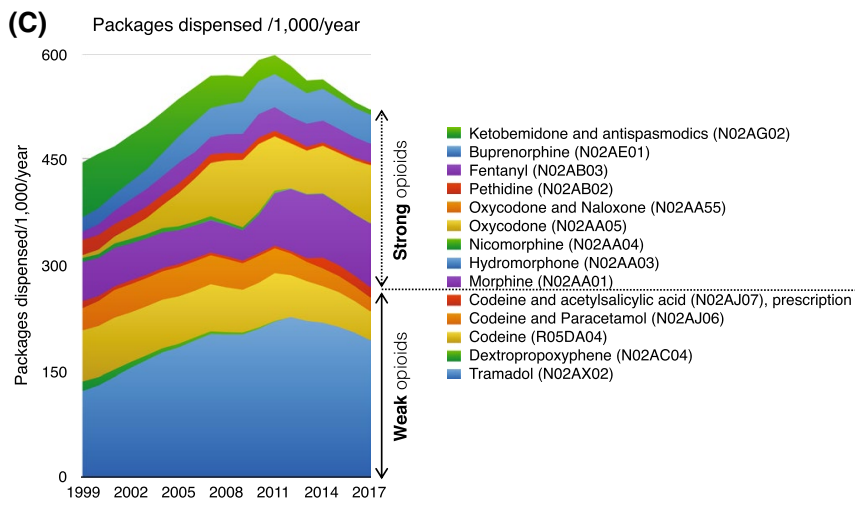

day, and c packages dispensed/1000/year [18]. $D D D$ defined daily dose, $O M E Q$ oral morphine equivalents. Metrics do not include overthe-counter sales of codeine and paracetamol combination products

morphine, oxycodone, and tramadol, and codeine and acetylsalicylic acid combination products according to all metrics employed

\subsection{Tramadol}

Tramadol utilisation metrics suggested a trend towards an increasing proportion of the population being treated with a higher dose or strength, in similar quantities per dispensing when comparing changes in volume and person metrics. The volume metric DDD/1000/day increased the most (146\%), followed by packages dispensed/1000/year (58\%), which was nearly equal to the person metric users/1000/year (55\%).

Stratifying for age, the proportional increase in volumemetric DDD/1000/year compared with the increase in person-metric users/1000/year was inversely correlated with increasing age, implying that, with decreasing age groups, there is a trend to prescribe tramadol to more users and at higher doses or strengths. There has been an increased focus on physical dependence on tramadol and reports of misuse of tramadol in some Middle Eastern and African countries [13, 24-26]. Further, the WHO expert committee on drug dependence has gradually acknowledged a potential for physical dependence on tramadol when used within the recommended dose range. The risk is still considered low compared with prototypical opioids [27], but it is likely to be dose related [24].

It has been proposed that the high utilisation of tramadol in Denmark is irrational, that the risk of physical dependence is not less than other opioids, and that tramadol is not superior in regards to analgesic or side effects [28]. This has likely prompted the recent monitoring of prescriptions of tramadol in Denmark. The high and increasing level of utilisation according to all metrics could also be a consequence of physician preference, which display significant national 
Table 1 Changes in opioid utilisation from 1999 to 2017 according to volume and person metrics, with interpretations of results based on relative changes [18]

\begin{tabular}{|c|c|c|c|c|c|c|}
\hline & \multicolumn{2}{|c|}{$\begin{array}{l}\text { DDD/1000/day }(\% \\
\text { change) }\end{array}$} & \multirow{2}{*}{$\begin{array}{l}\begin{array}{l}\text { Packages dis- } \\
\text { pensed/1000/year } \\
\text { (\% change) }\end{array} \\
62.7 \% \uparrow \uparrow \uparrow_{292 \%}\end{array}$} & \multicolumn{2}{|c|}{$\begin{array}{l}\text { Users/1000/year ( } \% \\
\text { change) }\end{array}$} & \multirow{2}{*}{$\begin{array}{l}\text { Comparison of metrics, interpretation } \\
\text { A larger increase in users and packages dispensed } \\
\text { than DDD } \\
\text { Suggests a trend to treat more patients, with lower } \\
\text { doses or strengths }\end{array}$} \\
\hline $\begin{array}{l}\text { Morphine } \\
\text { All age groups }\end{array}$ & $16.0 \%$ & $\uparrow_{\text {Ref. }}$ & & $159.3 \%$ & $\uparrow \uparrow \uparrow_{897 \%}$ & \\
\hline $\begin{array}{l}\text { Age } 0-64 \\
\text { Age } 65-79 \\
\text { Age } \geq 80\end{array}$ & $\begin{array}{r}21.9 \% \\
-12.1 \% \\
-17.8 \%\end{array}$ & $\begin{array}{l}\uparrow_{\text {Ref. }} \\
\downarrow_{\text {Ref. }} \\
\downarrow_{\text {Ref. }}\end{array}$ & & $\begin{array}{l}209.0 \% \\
78.1 \%\end{array}$ & $\begin{array}{l}\uparrow_{\uparrow} \uparrow_{855 \%} \\
\uparrow \uparrow \uparrow_{747 \%} \\
\uparrow \uparrow \uparrow_{734 \%}\end{array}$ & $\begin{array}{l}\text { A larger increase in users than DDD in the } \\
<65 \text { years group } \\
\text { Suggests a trend to treat those aged } \geq 65 \text { years with } \\
\text { higher strengths and/or doses vs. the } 0-64 \text { years } \\
\text { group }\end{array}$ \\
\hline $\begin{array}{l}\text { Oxycodone } \\
\text { All age groups }\end{array}$ & $1151.9 \%$ & $\uparrow_{\text {Ref. }}$ & $1974.6 \% \uparrow_{71 \%}$ & $1734.6 \%$ & $\uparrow \uparrow 51 \%$ & $\begin{array}{l}\text { A smaller increase in DDD than packages dispensed } \\
\text { and users } \\
\text { Suggests a trend to treat more patients with slightly } \\
\text { smaller doses and/or strengths }{ }^{\mathrm{a}}\end{array}$ \\
\hline $\begin{array}{l}\text { Age } 0-64 \\
\text { Age } 65-79 \\
\text { Age } \geq 80\end{array}$ & $\begin{array}{c}1262.3 \% \\
758.4 \% \\
1053.1 \%\end{array}$ & $\begin{array}{l}\uparrow_{\text {Ref. }} \\
\uparrow_{\text {Ref. }} \\
\uparrow_{\text {Ref. }}\end{array}$ & & $\begin{array}{l}2054.7 \% \\
1139.3 \% \\
1390.7 \%\end{array}$ & $\begin{array}{l}\uparrow_{63 \%} \\
\uparrow \uparrow_{50 \%} \\
\uparrow_{32 \%}\end{array}$ & $\begin{array}{l}\text { A smaller increase in DDD than users among the age } \\
\text { group 0-79 years. Suggests a trend to treat those } \\
\text { aged } 0-79 \text { years with lesser doses and/or strengths } \\
\text { vs. those aged } \geq 80 \text { years. The overall increase in } \\
\text { users was prompted by a likely trend to treat more } \\
\text { patients aged } 0-64 \text { years }\end{array}$ \\
\hline $\begin{array}{l}\text { Tramadol } \\
\text { All age groups }\end{array}$ & $146.0 \%$ & $\uparrow \uparrow \uparrow_{168 \%}$ & $58.4 \% \uparrow_{7 \%}$ & $54.6 \%$ & $\uparrow_{\text {Ref. }}$ & $\begin{array}{l}\text { A larger increase in DDD than users and packages } \\
\text { dispensed } \\
\text { Suggests a trend to treat more patients with higher } \\
\text { doses and/or strengths }\end{array}$ \\
\hline $\begin{array}{l}\text { Age } 0-64 \\
\text { Age } 65-79 \\
\text { Age } \geq 80\end{array}$ & $\begin{array}{r}171.7 \% \\
80.6 \% \\
44.8 \%\end{array}$ & $\begin{array}{l}\uparrow_{\uparrow} \uparrow_{176 \%} \\
\uparrow \uparrow \uparrow_{215 \%} \\
\uparrow \uparrow_{136 \%}\end{array}$ & & $\begin{array}{l}62.1 \% \\
25.6 \% \\
19.0 \%\end{array}$ & $\begin{array}{l}\uparrow_{\text {Ref. }} \\
\uparrow_{\text {Ref. }} \\
\uparrow_{\text {Ref. }}\end{array}$ & $\begin{array}{l}\text { A larger increase in DDD than users for all groups, } \\
\text { though less pronounced with increasing age. } \\
\text { Suggests a trend to treat those aged 0-79 years } \\
\text { with higher doses and/or strengths vs. those aged } \\
\geq 80 \text { years }\end{array}$ \\
\hline $\begin{array}{l}\text { Codeine } \\
\text { All age groups }\end{array}$ & $-42.6 \%$ & $\downarrow_{\text {Ref. }}$ & $-43.4 \% \downarrow_{-2 \%}$ & $-44.4 \%$ & $\downarrow_{-4 \%}$ & $\begin{array}{l}\text { Nearly equal decreases in DDDs, users, and pack- } \\
\text { ages dispensed } \\
\text { Suggests a trend to treat fewer patients without a } \\
\text { trend of changing doses and/or strengths }\end{array}$ \\
\hline $\begin{array}{l}\text { Age } 0-64 \\
\text { Age } 65-79 \\
\text { Age } \geq 80\end{array}$ & $\begin{array}{l}-45.9 \% \\
-43.9 \% \\
-53.3 \%\end{array}$ & $\begin{array}{l}\downarrow_{\text {Ref. }} \\
\downarrow_{-3 \%} \\
\downarrow \downarrow-38 \%\end{array}$ & & $\begin{array}{l}-50.8 \% \\
-42.6 \% \\
-38.7 \%\end{array}$ & $\begin{array}{l}\downarrow_{-11 \%} \\
\downarrow_{\text {Ref. }} \\
\downarrow_{\text {Ref. }}\end{array}$ & $\begin{array}{l}\text { A larger decrease in DDD than users, similar for all } \\
\text { age groups } \\
\text { Suggests no apparent age-related utilisation trends }\end{array}$ \\
\hline $\begin{array}{l}\text { Codeine and ASA } \\
\text { All age groups }\end{array}$ & $466.3 \%$ & $\uparrow \uparrow \uparrow_{994 \%}$ & $42.6 \% \uparrow_{\text {Ref. }}$ & $264.2 \%$ & $\uparrow \uparrow \uparrow_{520 \%}$ & $\begin{array}{l}\text { A larger increase in DDD than users and much } \\
\text { smaller increase of packages dispensed than DDD. } \\
\text { Suggests a trend to treat more patients with higher } \\
\text { doses and/or strengths }\end{array}$ \\
\hline Age $0-64$ & $582.5 \%$ & $\uparrow \uparrow 70 \%$ & & $342.2 \%$ & $\uparrow_{\text {Ref. }}$ & A larger increase in DDD than users among those \\
\hline Age $65-79$ & $462.9 \%$ & $\uparrow \uparrow_{85 \%}$ & & $250.3 \%$ & $\uparrow_{\text {Ref. }}$ & aged $\geq 80$ years. Suggests a trend to treat those \\
\hline Age $\geq 80$ & $83.3 \%$ & $\uparrow \uparrow \uparrow_{256 \%}$ & & $23.4 \%$ & $\uparrow_{\text {Ref. }}$ & $\begin{array}{l}\text { aged } \geq 80 \text { years with higher doses and/or strengths } \\
\text { than } 0-79 \text { years. The overall increase in users was } \\
\text { prompted by a likely trend to treat more patients } \\
\text { aged } 0-79 \text { years }\end{array}$ \\
\hline $\begin{array}{l}\text { Codeine and ASA, OTC } \\
\text { All age groups }\end{array}$ & $-77.9 \%$ & $\downarrow \downarrow \downarrow-386 \%$ & $-17.0 \% \downarrow_{\text {Ref. }}$ & N.A. & & $\begin{array}{l}\text { A larger decrease in DDD vs. packages dispensed. } \\
\text { Suggests a trend to purchase smaller doses per } \\
\text { package }\end{array}$ \\
\hline $\begin{array}{l}\text { Codeine and paracetamol } \\
\text { All age groups }\end{array}$ & $-9.5 \%$ & $\downarrow_{\text {Ref. }}$ & $-37.6 \% \quad \downarrow \downarrow \downarrow \downarrow_{296 \%}$ & $-64.8 \%$ & $\downarrow \downarrow \downarrow_{-582 \%}$ & $\begin{array}{l}\text { A larger decrease in users than DDD, and larger } \\
\text { decrease of packages dispensed than DDD. Sug- } \\
\text { gests a trend to treat fewer patients with increasing } \\
\text { doses and/or strengths }\end{array}$ \\
\hline
\end{tabular}


Table 1 (continued)

\begin{tabular}{|c|c|c|c|c|}
\hline & $\begin{array}{l}\text { DDD/1000/day (\% } \\
\text { change) }\end{array}$ & $\begin{array}{l}\text { Packages dis- } \\
\text { pensed } / 1000 / \text { year } \\
\text { ( } \% \text { change) }\end{array}$ & $\begin{array}{l}\text { Users/1000/year (\% } \\
\text { change) }\end{array}$ & Comparison of metrics, interpretation \\
\hline Age 0-64 & $1.7 \%$ & & $\downarrow \downarrow \downarrow-3973 \%$ & \multirow{3}{*}{$\begin{array}{l}\text { A larger decrease in users than DDD, less pro- } \\
\text { nounced with increasing age. Suggests the trend to } \\
\text { treat fewer patients with increasing doses and/or } \\
\text { strengths is more pronounced with decreasing age }\end{array}$} \\
\hline Age $65-79$ & $-26.1 \% \downarrow_{\text {Ref. }}$ & & $\downarrow \downarrow \downarrow-151 \%$ & \\
\hline Age $\geq 80$ & $-46.7 \% \downarrow_{\text {Ref. }}$ & & $-66.7 \% \downarrow_{-43 \%}$ & \\
\hline
\end{tabular}

Arrows approximate the relative changes within one row, i.e. one type of opioid or one age group, the reference for relative change is the metric with the least change during the period. Relative change is calculated by: Relative change in percent $=\frac{x-x_{\mathrm{ref}}}{\left|x_{\mathrm{ref}}\right|} \times 100$. Relative change and which metric represents the reference $\left(x_{r e f}\right)$ is denoted beside the arrows in subscript. Arrows visually indicate relative change according to the following parameters: $\uparrow$ indicates $0-50 \%, \uparrow \uparrow$ indicates $50-150 \%$, $\uparrow \uparrow \uparrow$ indicates $>150 \%$; $\downarrow$ indicates -50 to $0 \%$, $\downarrow \downarrow$ indicates -150 to $-50 \%$, $\downarrow \downarrow \downarrow$ indicates $<-150 \%$

$A S A$ acetylsalicylic acid, $D D D$ defined daily dose, OTC over-the counter

${ }^{a}$ Oxycodone has a DDD/median dose in non-cancer populations of 1.9 vs. 1.3 for morphine and 1.0 for tramadol [15], hence DDD/1000/day for oxycodone underestimates the use vs. morphine and tramadol [20]

${ }^{\mathrm{b}}$ For codeine and ASA, the proportion sold on prescription increased from 3 to $24 \%$ in 2017

differences and seem to change over time [29], or tramadol might simply be the opioid physicians know best.

\subsection{Codeine and Combination Products}

For codeine, the changes in utilisation trends were proportional, nearly equal, for all metrics and when stratified for age (Table 1). This suggests a trend of decreasing utilisation, with no change in treatment- or prescription-related factors, and no obvious age-dependent trends to consider.

Utilisation of codeine and paracetamol combination products displayed a pattern of relative changes with primarily declining person metrics, users/1000/year ( $-65 \%)$, followed by packages dispensed/1000/year (-38\%) and DDD/1000/ day $(-9.5 \%)$ (Table 1$)$. This suggests a trend of treating fewer with higher doses or strengths and higher quantities per dispensing. Age stratification revealed a trend of reduced doses with increasing age groups.

Prescription of codeine and acetylsalicylic acid combination products is linked to OTC sales. Utilisation according to $\mathrm{DDD} / 1000 /$ day stagnated for OTC sales, and the prescribed volume increased and stagnated after the introduction of limitations on OTC sales in 2013 (Fig. 1 in the ESM). For prescription dispensing, utilisation according to packages dispensed increased much less than all other metrics (Table 1). This suggests a trend to treat more with higher doses or strengths, in much higher quantities per dispensing, compatible with the introduction of limitations on OTC sales, as users previously relying on OTC sales, are likely to instead obtain codeine and paracetamol on prescription.

Overall, the utilisation of codeine and combinations is declining, despite observed increases in prescriptions for codeine and acetylsalicylic acid combination products.

\subsection{Morphine}

We found a larger increase in users/1000/year (159\%) than both packages dispensed/1000/year (63\%) and DDD/1000/ day (16\%) (Table 1), suggesting an overall trend to treat more with morphine but likely with smaller doses or strengths. Only $5.2 \%$ of all dispensing in the period was for parenteral morphine, which has a conversion factor of 0.9 and therefore does not have a significant impact on this interpretation (Table 1 in the ESM). There does not seem to be significant age-related utilisation trends, though the relative change when comparing users/1000/year with DDD/1000/ day was slightly larger for the age groups $\geq 65$ years. This suggests a minor trend to treat these groups at higher doses or strengths than for the age group 0-64 years.

\subsection{Oxycodone}

Comparing non-age stratified metrics for oxycodone, the most prominent increase was for packages dispensed/1000/ year (1974\%), followed by users/1000/day (1734\%). This indicates an overall trend to prescribe oxycodone to more patients, but likely at lower quantities per dispensing.

A comparatively small increase of $\mathrm{DDD} / 1000 /$ day (1151\%) suggests lesser average prescribed dosing or strength compared with 1999. But it should be considered that oxycodone has a DDD/median dose in the non-cancer population of 1.9 compared with 1.3 for morphine and 1.0 for tramadol [15]. We thus risk underestimating the utilisation of oxycodone in comparison with these opioids.

This drug was first synthesised a century ago but, in the observed period, the increase in oxycodone utilisation according to the reference metric DDD/1000/day reflected the introduction of Oxycontin and Oxynorm. Since 2010, 
these two products have gradually been replaced by other oxycodone products. Comparing oxycodone with morphine, the two drugs seem to "switch", in terms of both volume and person metrics for all age groups around 2008. The Danish Health Authority considers this to be the consequence of an effort in regional health districts and hospital management to reduce oxycodone utilisation due to high relative pricing [30].

Stratifying for age, there is a trend of decreasing doses or strength with decreasing age and nearly no change over time in dosing or strength per user among those aged $\geq 80$ years.

\subsection{Global Ranking According to the Defined Daily Dose (DDD) Metric}

Given the high global ranking for legal sales of opioids in 2017 [2], it might be tempting to conclude irrational prescriber behaviour for opioids in Denmark. However, the global comparison includes use of opioids in animals, use for anaesthesia, and pharmaceutical production and does not solely reflect the use of opioids for analgesic treatment [2, $3]$. The UN does not monitor analgesics, but does monitor narcotic drugs, according to the 1961 Convention for Drug Control [31], and as such, their data are not optimal for use in arguments about prescriber behaviour. All Nordic countries except Finland are included in the global top 20, indicating that a high ranking might simply reflect financial prosperity and access to sufficient, not necessarily irrational, amounts of opioids $[4,32]$.

\subsection{Aging}

The prevalence of pain is closely linked to the age composition of the population [34], compatible with the higher utilisation metrics for both volume and people with increasing age observed in Fig. 2.

Opioids seem to be effective against diseases that are highly prevalent in old age, i.e. osteoarthritis, vertebral fractures, herpes zoster, and rheumatoid arthritis [1], though studies on older populations are insufficient [35]. The recent national guideline has little focus on age and the complexities this brings [9,35], likely due to lack of evidence. Currently, tramadol seems to be the de-facto first-choice opioid, utilised significantly more according to both volume and users/1000/year, and comprises a prime target for regulatory efforts on prescriber behaviour. This has been set in motion nationally by monitoring prescriptions and publishing new guidelines [9], and internationally by critical review by the WHO [27]. Assessing the effects of introducing a pain management guideline on utilisation would require yearlong follow-up, as practical de-escalation of medications for chronic or severe pain requires multiple re-evaluations by the prescriber [10]. Furthermore, maintaining adherence to pain management guidelines might be more difficult in an environment where opioids are affordable [33]. In the near future, the method of analysis employed in this study could be utilised as one aspect in the evaluation of guidelines.

The fact that a decline in the use of tramadol in both DDD/1000/day and users/1000/year was seen between 2016 and 2017 (Figs. 1,2) indicates that part of the population might have been prescribed too much tramadol, regardless of age. For the older population, the high utilisation of opioids is probably ameliorated by attitudes towards pain changing with increasing age. In a qualitative study regarding back pain among older patients with a median age of 83 years, respondents had negative attitudes towards the use of analgesics, accepting pain as an inevitability of old age [36].

\subsection{Comparison to Other Studies on Opioid Utilisation Trends}

Others have also found that tramadol is the most utilised opioid in terms of volume metrics, establishing that preferences for tramadol are similar in Norway and Sweden [29]. A report in Danish [37] also examined differences in volume- and person-metric trends from 2003 to 2013 using the same dataset as this study, though without comparison of proportional changes. Here, it was evident that tramadol, morphine, and oxycodone were increasingly popular among prescribers. It was speculated that the primary explanation for the increased opioid utilisation according to DDD/1000/ day was an aging population and tramadol being prescribed instead of non-steroidal anti-inflammatory drugs (NSAIDs). Our study does not support the notion that increasing opioid utilisation was due to an aging population, instead indicating that utilisation of the selected opioids increased most for the age group 0-64 years. The tendency of age-related trends in dose or strength over time for tramadol and oxycodone will not be evident when examining utilisation trends independently. Our data do not allow speculation on opioid and NSAID utilisation trends.

A study in Australia, using the same analysis method as our study, without age stratification, from 2006 to 2015 [20] found that, for oxycodone, there was a pattern of proportionality of trends similar to our study. However, for tramadol, the utilisation trends were nearly proportional, unlike our finding. Hence, oxycodone was also used in a growing population in declining doses or strengths, whereas tramadol utilisation did not display a trend of increasing doses or strengths.

\subsection{Strengths and Limitations}

The major strength of this study was our access to population-based nationwide aggregated wholesale data linked 
(A)

2000

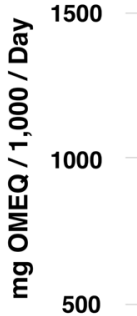

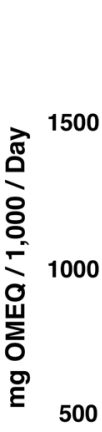

$0-64$ years

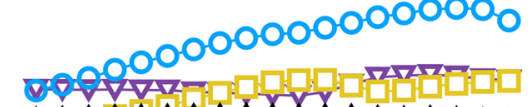

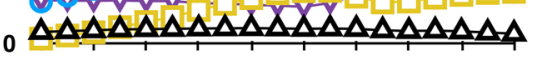

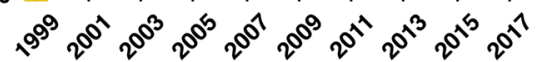

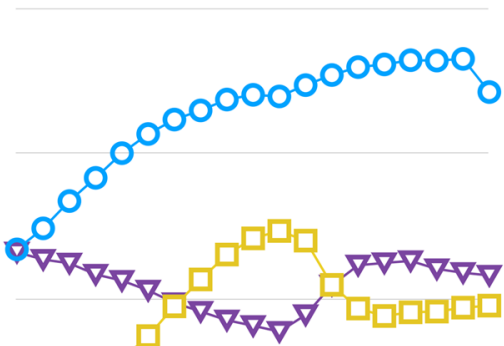

65-79 years

- Tramadol (N02AX02)

$\forall$ Morphine (N02AA01)

$\geq 80$ years

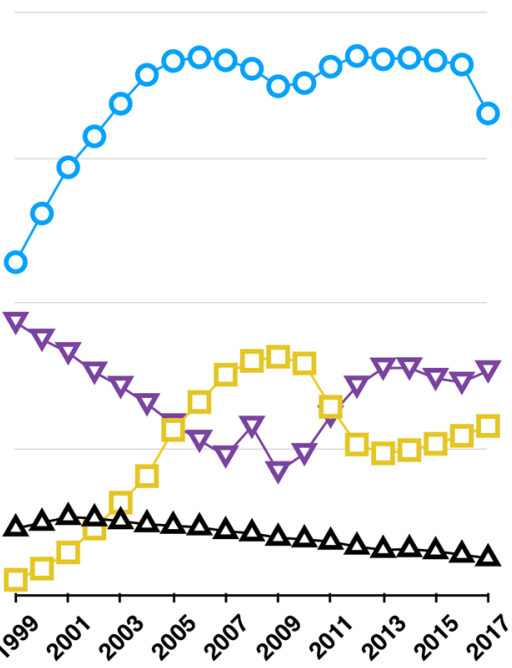

$\triangle$ Codeine (R05DA04)

$\approx$ Morphine (N02AA01)

- Tramadol (NO2AX02)

* Codeine and acetylsalicylic acid (N02AJ07), prescription

ㅁ. Oxycodone (N02AA05)

+ Codeine and paracetamol (N02AJ06)

(B)

0-64 years

65-79 years

$\geq 80$ years

180.0

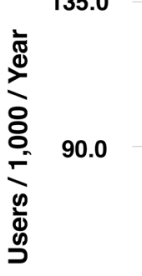

135.0

$\Delta \Delta \Delta \Delta \Delta \Delta \Delta \Delta \Delta \Delta \Delta \Delta \Delta \Delta \Delta \Delta \Delta \Delta \Delta$

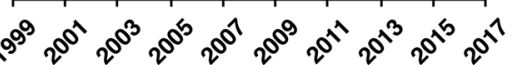

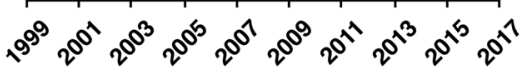

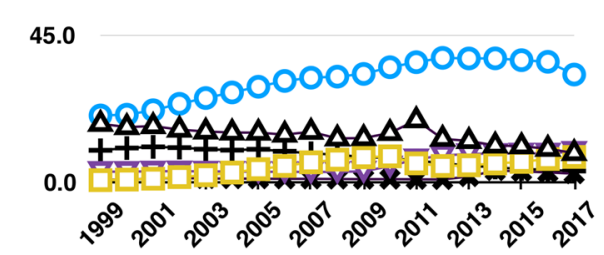

45.0

Fig. 2 Trends over time in prescription dispensing [18] according to a OMEQ/1000/day and $\mathbf{b}$ prevalence proportion according to users/1000/day of the most commonly used opioids stratified by age groups. a Prescription dispensing according to OMEQ/1000/ day of tramadol (N02AX02) (circles), codeine and combination products (R05DA04, N02AJ06 and N02AJ07) (triangles), morphine (N02AA01) (inverted triangles), and oxycodone (N02AA05) (squares) for age groups 0-64 years, 65-79 years, and $\geq 80$ years. Complete data for all investigated opioids are available in Table 4

to individual characteristics. However, our study also has several limitations.

Any study on drug utilisation statistics without access to individual-level data will be unable to assess the quality in the Electronic Supplementary Material. b Prevalence proportion according to users/1000/day of tramadol (N02AX02) (circles), codeine (R05DA04) (triangles), codeine and paracetamol combination products (N02AJ06) (plus signs), codeine and acetylsalicylic acid combinations (N02AJ07) (crosses), morphine (N02AA01) (inverted triangles), and oxycodone (N02AA05) (squares) for age groups 0-64 years, $65-79$ years, and $\geq 80$ years. Metrics do not include overthe-counter sales of codeine and paracetamol combination products. $O M E Q$ oral morphine equivalents

of opioid prescribing. Nor will it be possible to definitively identify irrational prescriber behaviour. This would require detailed knowledge of predisposing conditions and long-term follow-up with both quantitative and qualitative 
methods. Hence, studies on drug utilisation statistics primarily allow some insight into medical culture and attitudes [29].

We converted DDDs to OMEQs in this study when displaying opioids of varying potency, as in Figs. 1 and 2. This allows for a better comparison of utilisation despite differences in clinical potency [13, 14]. There is limited consensus on equianalgesic ratios $[38,39]$, but OMEQs are likely best applied in epidemiological research, as it could be argued that there are no universal conversion factors, only a median population-based estimate. We consider OMEQs the best currently acknowledged approach to compare opioids of varying potency. The estimate of equianalgesic ratio derived from population studies should not be applied in clinical practice without significant caution given the variability in acquired tolerance, drug interactions, metabolism, body composition, and pain control [40], and that equianalgesic ratios cannot be considered bi-directional [39].

Furthermore, this study assumes proportional changes in prevalence of different severities of pain.

This assumption might be wrong and would require structured interviews and stringent quantification of pain on a large scale. A recent attempt to examine the prevalence of different severities of pain in the USA [41] found a nearly proportional increasing prevalence of all severities of pain. Hence, the assumption of proportional increases is likely to remain valid for our study.

Choosing to single out the four opioids with the highest number of users/1000/year in 2017 ensured the focus remained on utilisation patterns of the opioids most used by most prescribers; notably, though, we missed fentanyl. In the age group $\geq 80$ years, fentanyl was dispensed in quantities surpassing those of morphine in DDD and OMEQs but only one-third of morphine when measured with users/1000/year (Tables 2 and 3 in the ESM), making it equally tempting to address in future guidelines regarding opioid treatment in old age.

Methadone (N07BC02) utilisation according to DDD/1000/ day was significant, but we did not analyse this opioid in this study because it is largely used for treatment of opioid addiction. The exact proportion used for treatment of opioid addiction is unknown but considered to be the vast majority, and only about $50 \%$ can be linked to individual-level data, as the rest is distributed from clinics for substance abuse according to a recent report on Danish opioid utilisation [37]. This might have interfered with the results albeit probably only marginally, as methadone users outside addiction treatment comprise a clear minority (most often palliative patients) and would not have been included as any of the four opioids selected for analysis in Table 1.

Finally, we assumed consumption of opioids after collection of the prescription, which might bias the data towards a marginal overestimation of consumption.

\section{Conclusion}

Tramadol is the most utilised opioid in Denmark and was prescribed at increasing doses or strengths over the study period. This was most pronounced for the younger $(<80$ years) age groups. Oxycodone was prescribed at decreasing doses or strengths over time, but this was nearly unchanged for the age group $\geq 80$ years. There is a need to address the pharmacological treatment of pain with regards to age, with tramadol and oxycodone being possible targets for regulatory efforts.

\section{Compliance with Ethical Standards}

Funding No sources of funding were used to conduct this study or prepare this manuscript.

Conflict of interest Søren Kabell Nissen, Anton Pottegård, and Jesper Ryg have no conflicts of interest that are directly relevant to the content of this study.

Ethical approval This study was based on aggregate data, and no ethical approval was necessary.

Data availability All data generated or analysed during this study are included in the paper or its supplementary files.

Open Access This article is distributed under the terms of the Creative Commons Attribution-NonCommercial 4.0 International License (http://creativecommons.org/licenses/by-nc/4.0/), which permits any noncommercial use, distribution, and reproduction in any medium, provided you give appropriate credit to the original author(s) and the source, provide a link to the Creative Commons license, and indicate if changes were made.

\section{References}

1. Breivik H, Collett B, Ventafridda V, Cohen R, Gallacher D. Survey of chronic pain in Europe: prevalence, impact on daily life, and treatment. Eur J Pain. 2006;10:287-333.

2. International Narcotics Control Board. Estimated World Opioid Requirements for 2018; 2018. Vienna: United Nations Publication; https://www.incb.org/incb/en/narcotic-drugs/Technical_ Reports/narcotic_drugs_reports.html. Accessed 10 Feb 2018.

3. Danish Health Authority. [Review of the Opioid Consumption in Denmark]; 2016. https://www.sst.dk/da/rationel-farmakoter api/smerteindsats. Accessed 11 Nov 2017.

4. Groth Clausen T, Eriksen J, Borgbjerg FM. Legal opioid consumption in Denmark 1981-1993. Eur J Clin Pharmacol. 1995;48:321-5

5. Okie S. A flood of opioids, a rising tide of deaths. N Engl J Med. 2010;363:1981-5.

6. Jones MR, Viswanath O, Peck J, Kaye AD, Gill JS, Simopoulos TT. A brief history of the opioid epidemic and strategies for pain medicine. Pain Ther. 2018;7:13-21.

7. Danish Health Authority. [Use of Opioids in Chronic Nociceptive, Non-Malignant Pain]. Inst. Ration. Pharmacother; 2018. https://www.sst.dk/da/rationel-farmakoterapi/maane dsbladet/2018/rationel-farmakoterapi-3,-2018/brug-af-opioi 
der-ved-kroniske-nociceptive,-ikke-maligne-smerter. Accessed 30 Oct 2018

8. Danish Health Authority. [Focus on Pain Management]. Inst. Ration. Pharmacother; 2017. https://www.sst.dk/da/rationelfarmakoterapi/smerteindsats. Accessed 30 Oct 2018.

9. Danish Health Authority. [National Clinical Guideline on Opioid Treatment of Chronic Non-Malignant Pain]; 2018. https:// www.sst.dk/da/udgivelser/2018/nkr-opioidbehandling-af-kroni ske-non-maligne-smerter. Accessed 1 Feb 2019.

10. Busse JW, Craigie S, Juurlink DN, Buckley DN, Wang L, Couban RJ, et al. Guideline for opioid therapy and chronic noncancer pain. CMAJ. 2017;189:E659-66.

11. Jarlbaek L, Kehlet H, Sjøgren P. The licit opioid consumption in Denmark. Ugeskr Laeger. 2010;172:3173-8.

12. WHO Collaborating Centre for Drug Statistics Methodology. Guidelines for ATC classification and DDD assignment 2019, Oslo; 2018.

13. Jarlbaek L, Andersen M, Hallas J, Engholm G, Kragstrup J. Use of opioids in a Danish population-based cohort of cancer patients. J Pain Symptom Manag. 2005;29:336-43.

14. Svendsen K, Borchgrevink P, Fredheim O, Hamunen K, Mellbye A, Dale O. Choosing the unit of measurement counts: the use of oral morphine equivalents in studies of opioid consumption is a useful addition to defined daily doses. Palliat Med. 2011;25:725-32.

15. Nielsen S, Gisev N, Bruno R, Hall W, Cohen M, Larance B, et al. Defined daily doses (DDD) do not accurately reflect opioid doses used in contemporary chronic pain treatment. Pharmacoepidemiol Drug Saf. 2017;26:587-91.

16. Eriksen J, Jensen MK, Sjøgren P, Ekholm O, Rasmussen NK. Epidemiology of chronic non-malignant pain in Denmark. Pain. 2003;106:221-8.

17. Inouye SK, Studenski S, Tinetti ME, Kuchel GA. Geriatric syndromes: clinical, research, and policy implications of a core geriatric concept. J Am Geriatr Soc. 2007;55:780-91.

18. The Danish Health Data Authority. Medical Statistics; 2018. http://medstat.dk/. Accessed 10 Feb 2019.

19. Schmidt M, Hallas J, Friis S. Potential of prescription registries to capture individual-level use of aspirin and other nonsteroidal anti-inflammatory drugs in Denmark: trends in utilization 1999-2012. Clin Epidemiol. 2014;6:155-68.

20. Karanges EA, Buckley NA, Brett J, Blanch B, Litchfield M, Degenhardt L, et al. Trends in opioid utilisation in Australia, 2006-2015: insights from multiple metrics. Pharmacoepidemiol Drug Saf. 2018;27:504-12.

21. Schmidt M, Hallas J, Laursen M, Friis S. Data Resource Profile: Danish online drug use statistics (MEDSTAT). Int J Epidemiol. 2016;45:1401-1402g.

22. Statistics Denmark. StatBank Denmark, Populations and elections, table FOLK2. Stat. Denmark; 2018. https://www.stati stikbanken.dk/SKADP02. Accessed 15 May 2018.

23. European Medicines Agency. Dextropropoxyphene I European Medicines Agency; 2009. https://www.ema.europa.eu/en/medic ines/human/referrals/dextropropoxyphene. Accessed 7 June 2019.

24. Lanier RK, Lofwall MR, Mintzer MZ, Bigelow GE, Strain EC. Physical dependence potential of daily tramadol dosing in humans. Psychopharmacology (Berl). 2010;211:457-66.

25. Läkemedelsverket. [The substance tramadol is now classified as a narcotic, same as codeine and dextropropoxifene].
Läkemedelsverket.se. 2008. Läkemedelsverket; https://lakem edelsverket.se/Alla-nyheter/NYHETER-2008/Substansen-trama dol-nu-narkotikaklassad-pa-samma-satt-som-kodein-och-dextr opropoxifen/. Accessed 2 Nov 2018.

26. World Health Organisation. Tramadol, Update Review Report, Thirty-sixth Meeting. Geneva: Switzerland; 2014.

27. World Health Organization. Critical Review Report: Tramadol Expert Committee on Drug Dependence, Forty-first Meeting; 2018.

28. Christrup L, Sædder EA. [Potential pharmacological consequences of the development of the opioid consumption in Denmark]. Ugeskr Laeger. 2017;179.

29. Jarlbaek L. Opioid prescribing habits differ between Denmark, Sweden and Norway - and they change over time. Scand J Pain. 2019;19:491-9.

30. The Reimbursement Committee. [Re-evaluation of reimbursement status for strong analgetics (opioids) i ATC-groups N02A, N07BC and R05DA]; 2011.

31. United Nations. The International Drug Control Conventions. United Nations Off. Drugs Crime; 2013. http://aip.scitation.org/ doi/10.1063/1.2770659. Accessed 11 Oct 2018.

32. Berterame S, Erthal J, Thomas J, Fellner S, Vosse B, Clare P, et al. Use of and barriers to access to opioid analgesics: a worldwide, regional, and national study. Lancet. 2016;387:1644-56.

33. Liebschutz JM, Xuan Z, Shanahan CW, LaRochelle M, Keosaian J, Beers D, et al. Improving adherence to long-term opioid therapy guidelines to reduce opioid misuse in primary care. JAMA Intern Med. 2017;02118:1265-72.

34. Kurita GP, Sjogren P, Juel K, Hojsted J, Ekholm O. The burden of chronic pain: a cross-sectional survey focussing on diseases, immigration, and opioid use. Pain. 2012;153:2332-8.

35. Pergolizzi J, Böger RH, Budd K, Dahan A, Erdine S, Hans G, et al. Opioids and the management of chronic severe pain in the elderly: consensus statement of an International Expert Panel with focus on the six clinically most often used World Health Organization Step III opioids (buprenorphine, fentanyl, hydromorphone, met). Pain Pract. 2008;8:287-313.

36. Makris UE, Higashi RT, Marks EG, Fraenkel L, Sale JEM, Gill TM, et al. Ageism, negative attitudes, and competing comorbidities - why older adults may not seek care for restricting back pain: a qualitative study. BMC Geriatr. 2015;15:1-9.

37. Jarlbæk L. Morphine-like drugs-an investigation of registrydata regarding consumption, users and age-distribution in Denmark 2003-2013; 2015. https://portal.findresearcher.sdu.dk/ $\mathrm{da} /$ publications/morfinlignende-lægemidler-en-unders $\varnothing$ gelse -af-registerdata-vedrøre. Accessed 29 May 2017.

38. Nielsen S, Degenhardt L, Hoban B, Gisev N. A synthesis of oral morphine equivalents (OME) for opioid utilisation studies. Pharmacoepidemiol Drug Saf. 2016;25:733-7.

39. Rennick A, Atkinson T, Cimino NM, Strassels SA, McPherson ML, Fudin J. Variability in opioid equivalence calculations. Pain Med (United States). 2016;17:892-8.

40. Nielsen LM, Olesen AE, Branford R, Christrup LL, Sato H, Drewes AM. Association between human pain-related genotypes and variability in opioid analgesia: an updated review. Pain Pract. 2015;15:580-94.

41. Nahin RL, Sayer B, Stussman BJ, Feinberg TM. Eighteen-year trends in the prevalence of, and health care use for, noncancer pain in the United States: data from the medical expenditure panel survey. J Pain. 2019;20:796-809. 